\title{
Why a Brazilian Consensus on Neuropathic Pain?
}

Por que um Consenso Brasileiro de Dor Neuropática?

Fulfilling its mission of "promoting the study of pain with excellence and ethics, acting as pioneers, sharing knowledge with other specialties, associating teaching and clinical practice, appreciating multiprofessional and multidisciplinary participation in humanized assistance, aiming at prevention and wellbeing with quality of life", the Brazilian Society for the Study of Pain (SBED), offers to all health professionals this Consensus on Neuropathic Pain.

The content will certainly add, for many years, knowledge on this type of pain which, in addition to causing distress to patients for being difficult to treat, is poorly known by most professionals not specialized in chronic pain management.

To prepare a comprehensive Neuropathic Pain Consensus, SBED has invited highly qualified Brazilian professionals, with excellent theoretic qualification and practical involvement with neuropathic pain management, because there are many ways and etiologies for the commonly called neuropathic pain.

This was a work demanding months to be developed, because neuropathic pain is challenging in its etiology, evaluation and management, which has required authors to spend several hours of literature research and reading to produce a high quality and updated text.

All articles part of this Revista Dor Supplement were evaluated by all authors and coauthors who could freely express their opinions and then were reviewed by members of the Board of Directors of the Brazilian Society for the Study of Pain and by the team of Journal advisors, for the material now presented to be, as it is, of high scientific and editorial quality.

We cannot but express our acknowledgment to Grümenthal do Brasil Farmacêutica Ltda., for the financial support for this Consensus to become reality.

Diretoria da Sociedade Brasileira para o Estudo da Dor 